Supplement of Clim. Past Discuss., 11, 3375-3424, 2015

http://www.clim-past-discuss.net/11/3375/2015/

doi:10.5194/cpd-11-3375-2015-supplement

(C) Author(s) 2015. CC Attribution 3.0 License.

(c) (1)

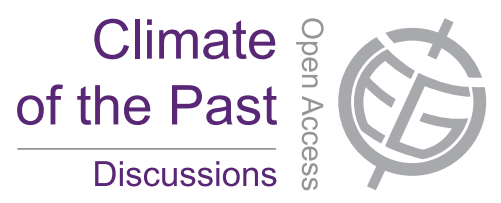

Supplement of

\title{
The influence of tropical volcanic eruptions on the climate of South Amer- ica during the last millennium
}

C. M. Colose et al.

Correspondence to: C. M. Colose (ccolose@albany.edu)

The copyright of individual parts of the supplement might differ from the CC-BY 3.0 licence. 


\section{Supplementary Figure Descriptions}

2 Fig. S1. Number of rain gauges per grid box for selected months (during eruption events)

3 in the GPCCV6 network. Bottom right panel shows a time-series of the total number of

4 stations over the range $90^{\circ}$ to $30^{\circ} \mathrm{W}$ and $60^{\circ} \mathrm{S}$ to $20^{\circ} \mathrm{N}$.

6 Fig. S2. Zonally averaged latitudinal AOD distribution for all 16 events used in each

7 ensemble member for DJF. Mean of all curves shown in dark black.

8

9 Fig. S3. As in Figure S2, but for JJA.

11 Fig. S4. Precipitation anomaly ( $\mathrm{mm} /$ day) for each volcanic eruption used in LM

12 composite (each averaged for the three ensemble members used) during DJF.

13

14 Fig. S5. As in Figure S4, but for JJA.

15

16 Fig. S6. Global-scale Precipitation Anomaly (mm/day) in the LM composite for a) DJF

17 and b) JJA 


\section{GPCC Gauge Density}
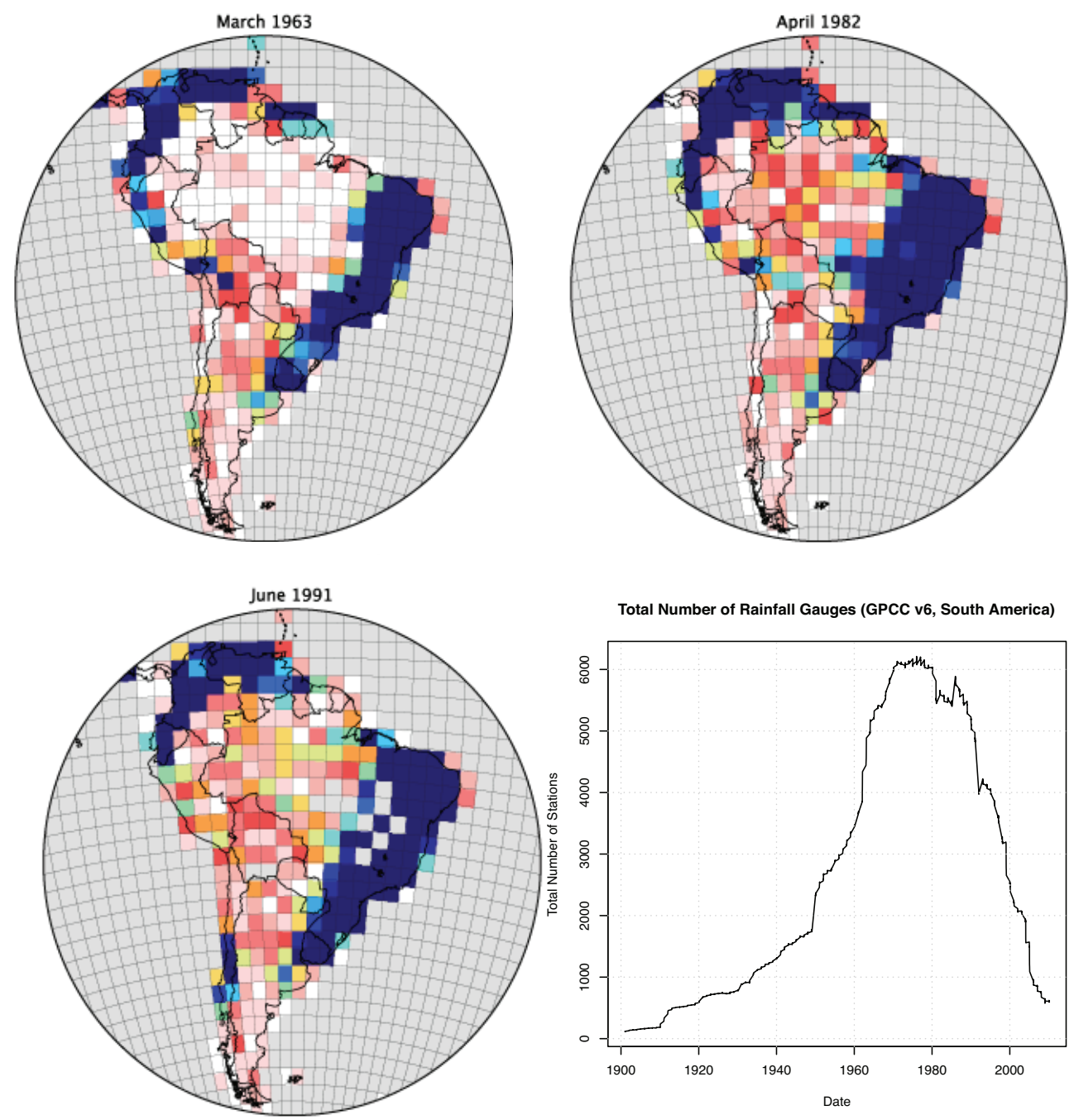

Number Gauges Per Grid Box

19 Fig. S1. Number of rain gauges per grid box for selected months (during eruption events) 20 in the GPCCv6 network. Bottom right panel shows a time-series of the total number of 21 stations over the range $90^{\circ}$ to $30^{\circ} \mathrm{W}$ and $60^{\circ} \mathrm{S}$ to $20^{\circ} \mathrm{N}$. 


\section{DJF Aerosol Optical Depth (Events in LM Composite)}

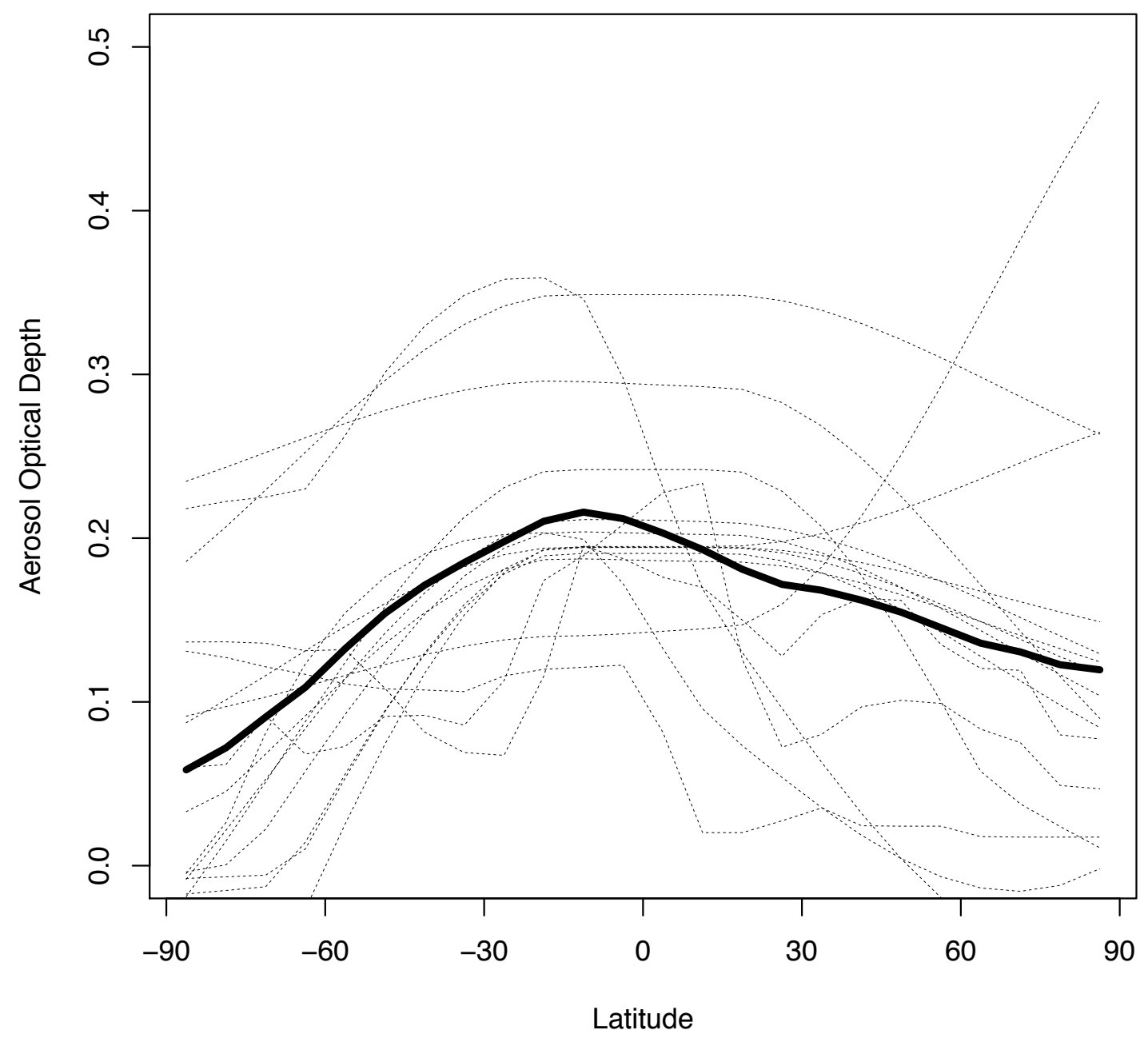

Fig. S2. Zonally averaged latitudinal AOD distribution for all 16 events used in each ensemble member for DJF. Mean of all curves shown in dark black. 


\section{JJA Aerosol Optical Depth (Events in LM Composite)}

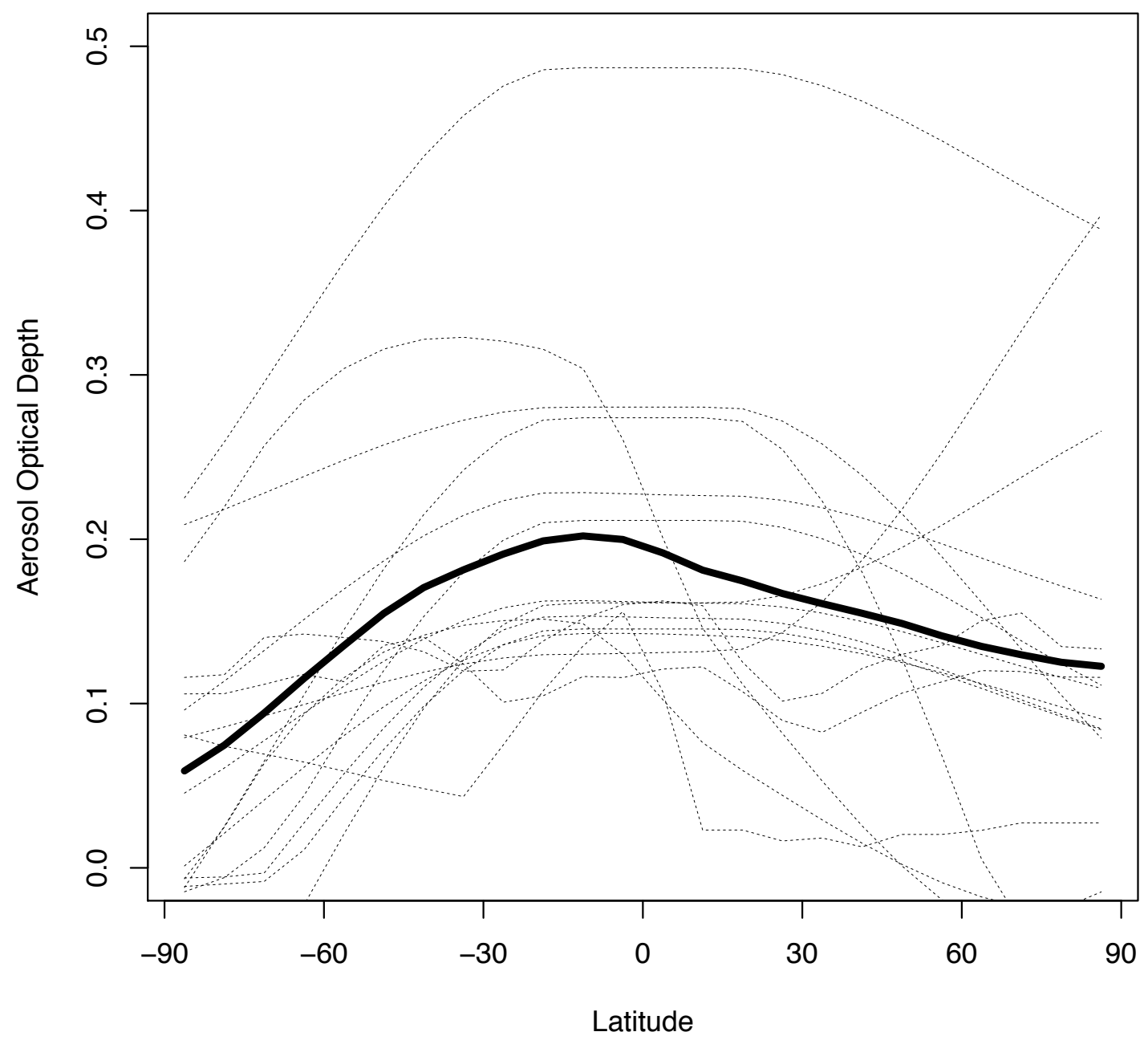

Fig. S3. As in Figure S2, but for JJA. 


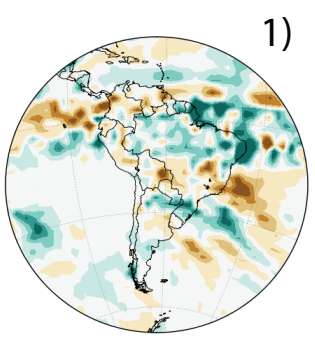

5)

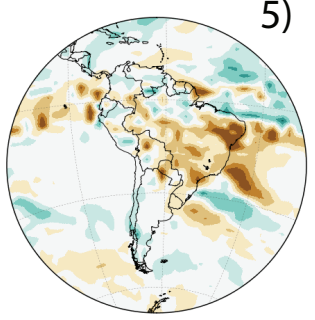

9)

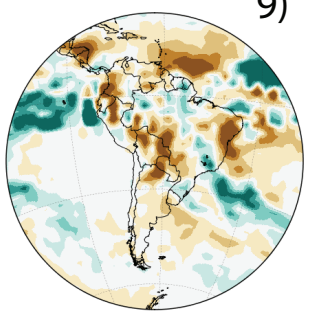

13)

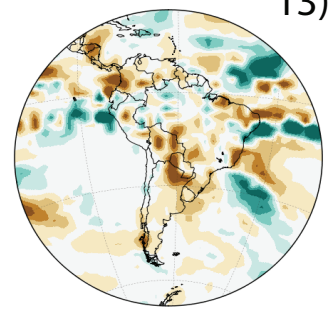

2)

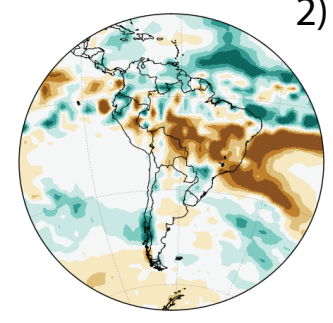

6)

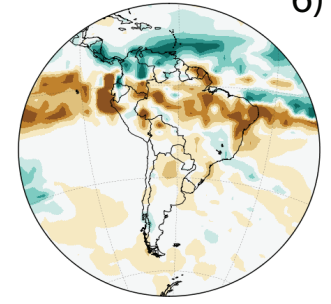

10)

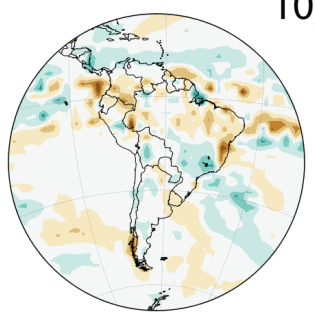

14)
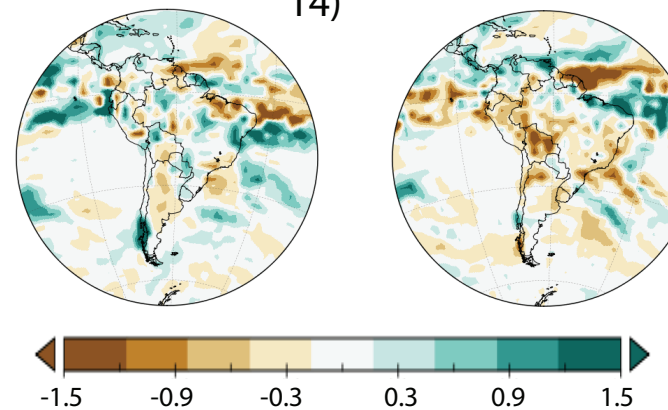

3)

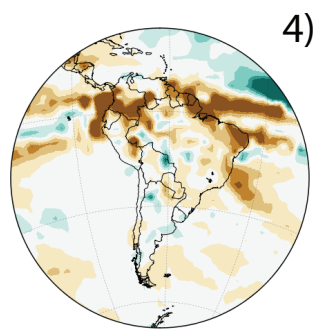

7)

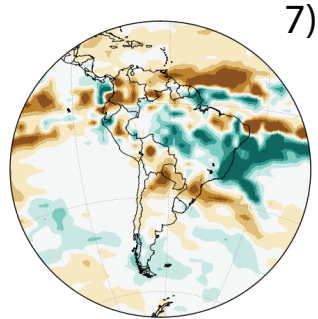

11)
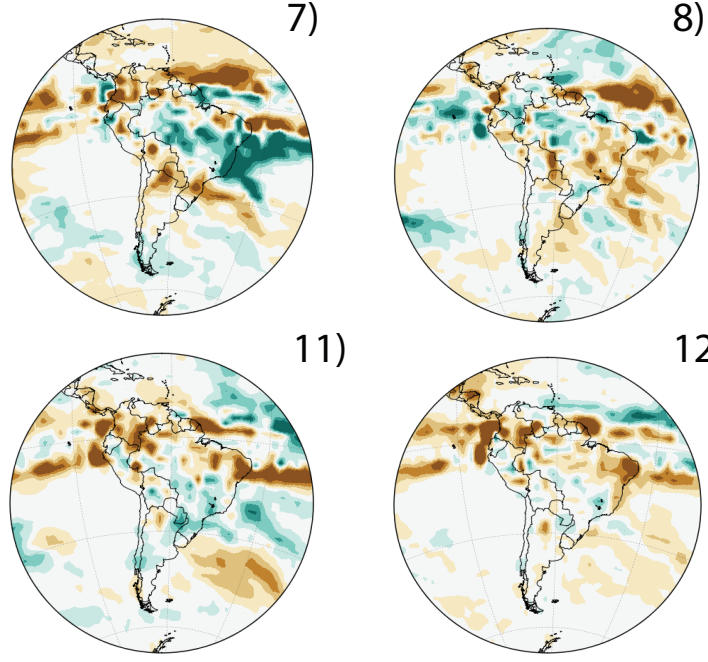

15)
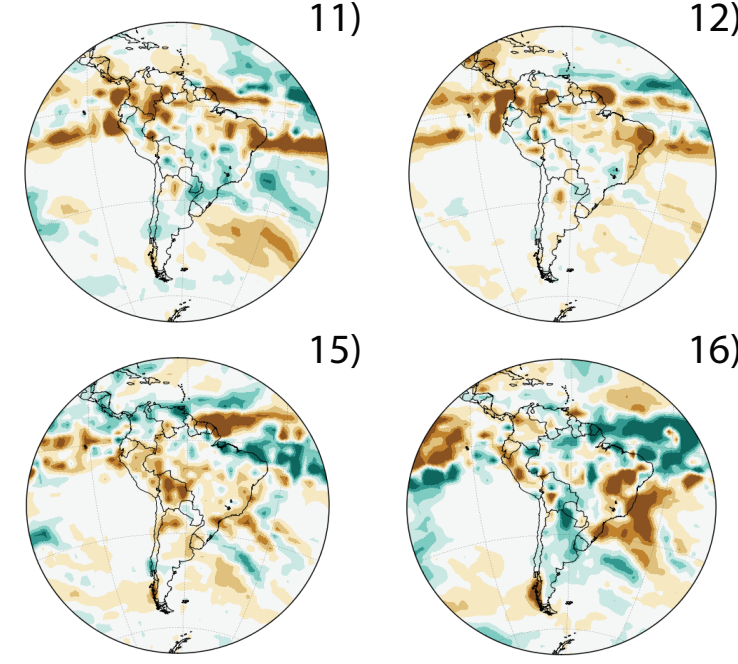

Fig. S4. Precipitation anomaly ( $\mathrm{mm} /$ day) for each volcanic eruption used in LM

32 composite (each averaged for the three ensemble members used) during DJF. 


\section{JJA PRECIPITATION BY EVENT}

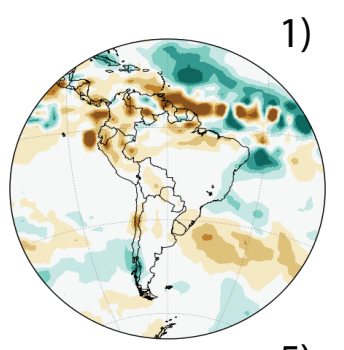

5)

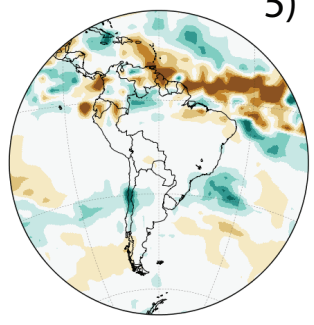

9)

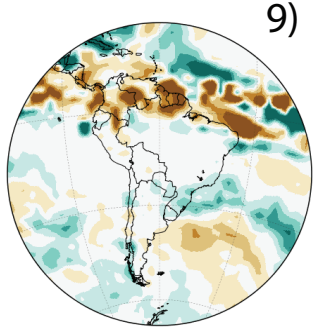

13)

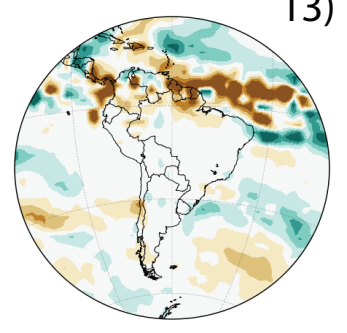

34

35

36
2)

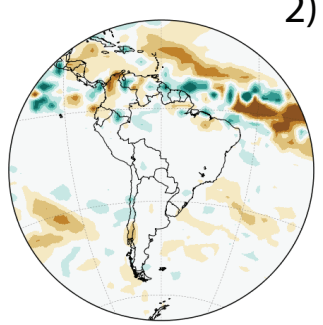

6)

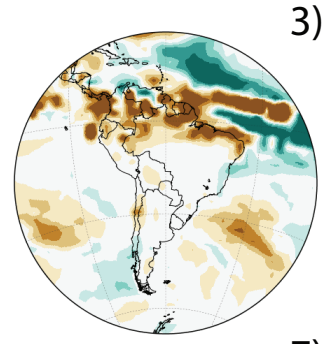

7)

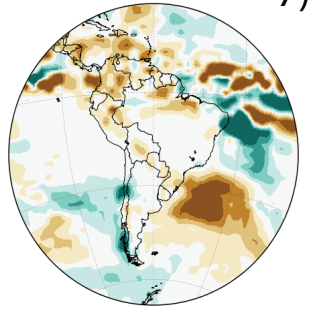

11)

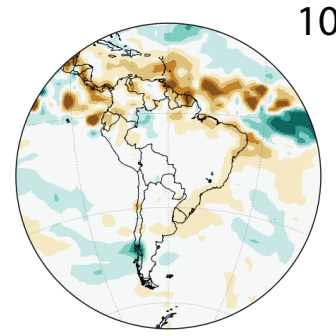

14)

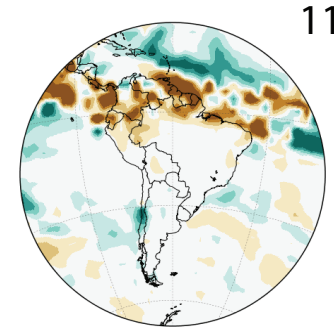

15)
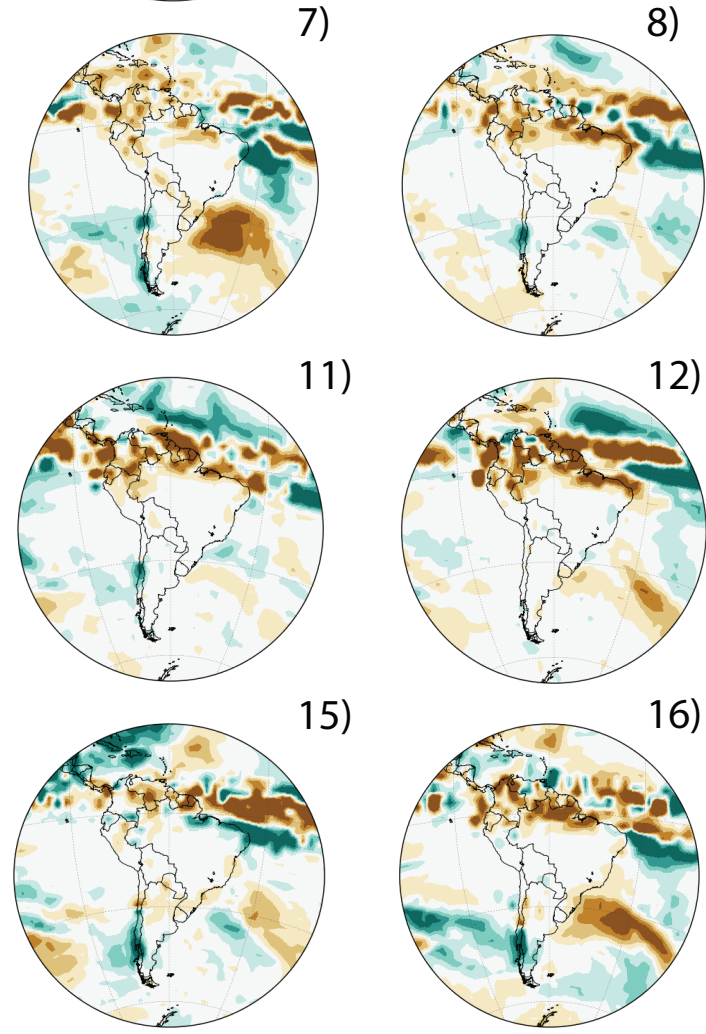

8)
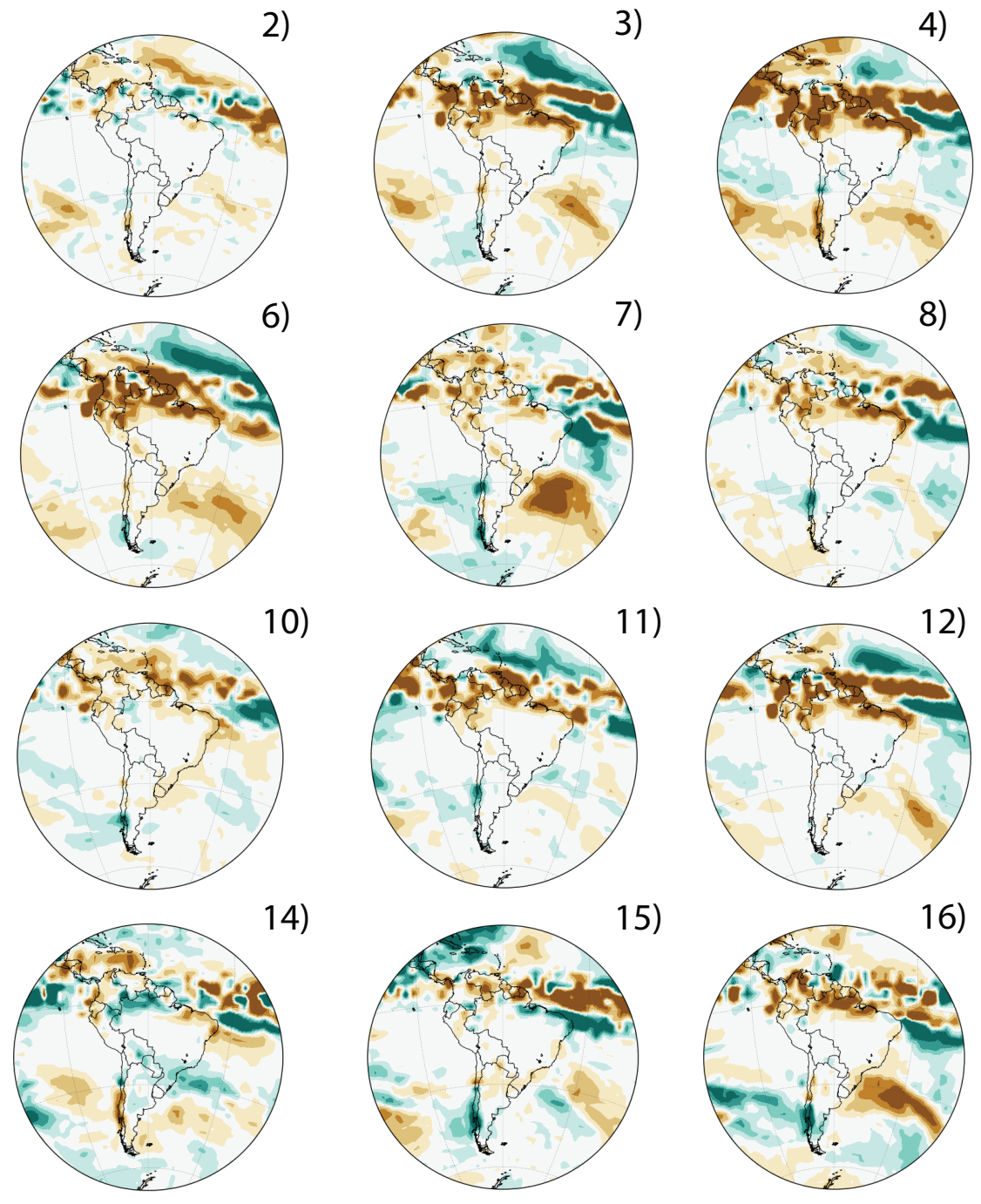

16)

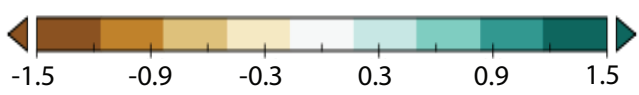

Fig. S5. As in Figure S4, but for JJA. 
Composite (ALL ERUP-GLOBAL) Precipitation
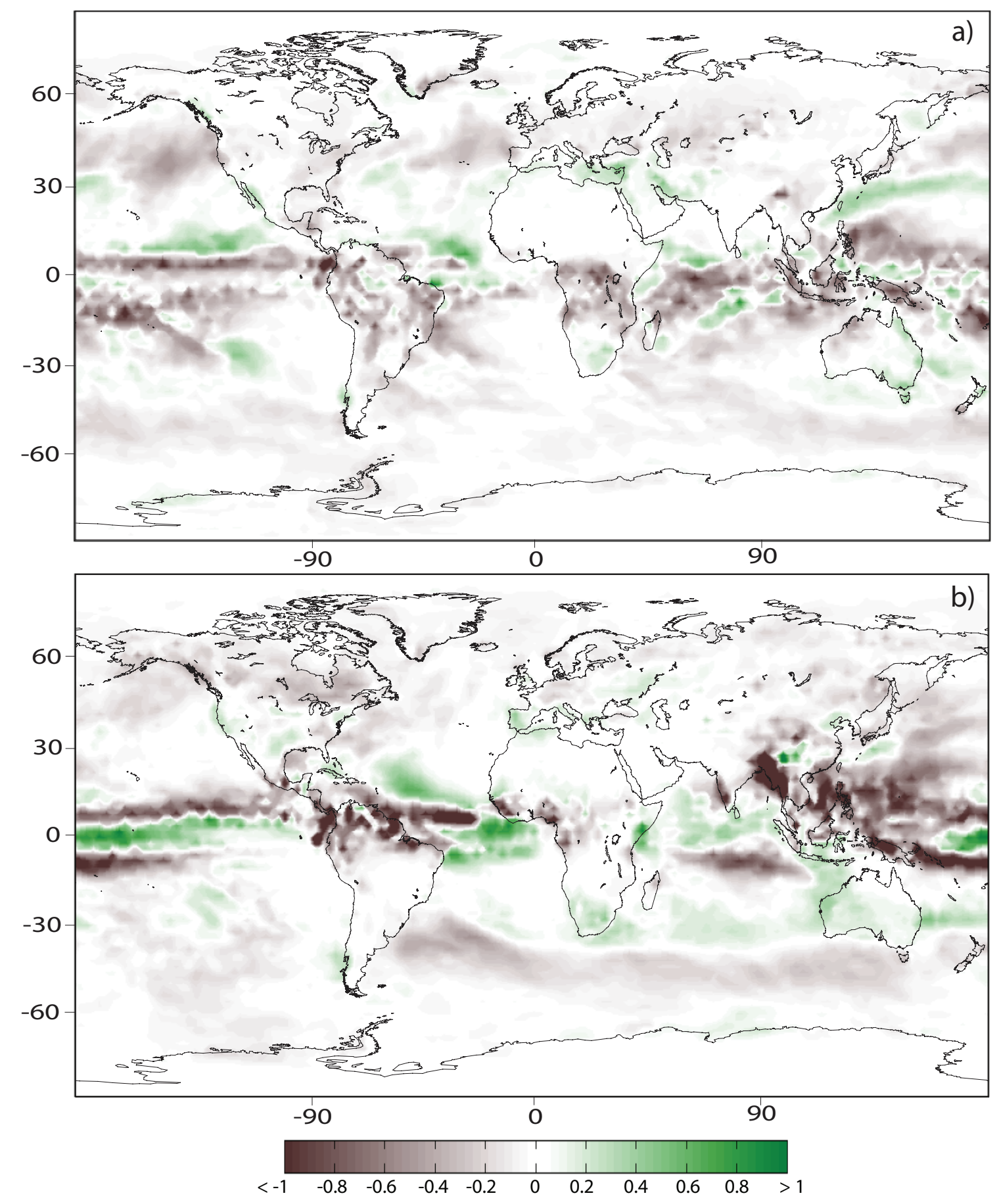

38 Fig. S6. Global-scale Precipitation Anomaly (mm/day) in the LM composite for a) DJF 39 and b) JJA 